\title{
Study and Practice of Teaching Reformation of Power System Load Forecast Course
}

\author{
Yajing Gao, Jing Zhu, Huaxin Cheng, Xiaobo Hu, Haifeng Liang \\ School of Electrical and Electronic Engineering \\ North China Electric Power University \\ Baoding, China \\ commoncat@163.com(Y.G.)
}

\begin{abstract}
Power System Load Forecast is a significant professional course opened for undergraduates especially students of the Department of Electrical Engineering, which involves Power System, Economic Management and Mathematics and so on, having plenty of different characteristics from other courses. On the background of smart grid, it is of great significance to carry on the teaching study and reform of this course in order to cultivate electric power talents suits the time. This paper puts out a reformation in teaching content, teaching method, and evaluation mode and so on, with questionnaires to analyze the effects of teaching reformation of this course.
\end{abstract}

Keywords-power system load forecast; teaching reformation; smart grid; questionnaire

\section{INTRODUCTION}

The load forecast of power system searches the internal relation between power load and its relative factors according to the varying pattern of historical data, which include power load, economy, society, meteorology, etc, so as to scientifically predict future power load. The load forecast has a great significance on the schedule, operation and control of power system and the improvement of prediction accuracy would enhance security level and economical efficiency of the power system's operation [1-2].

"Power System Load Forecasting" is a limited optional course for undergraduates of the Department of Electrical Engineering of North China Electric Power University, which starts in the second semester of third academic year and is available for students majoring in Power System and Automation, Power System Protective Relaying, High Voltage and Insulation Technology, Agricultural Electrification and Automation and so on. Over the years, this course, which contains 24 class hours and 1.5 credits, has been popular among undergraduates and the number of students was about 180 , which was close to the classroom capacity. Since there are so many students selecting this course, it has been a new thought direction of teaching reformation to search new strategies of teaching in class to ensure the interactive communication between teacher and students, which would also inspire students' enthusiasm and initiative and improve students' practical ability to guarantee effect of classroom teaching.

In addition, the forecast problems, including load forecast,

This work was supported by the Teaching Reformation Fund Project of North China Electric Power University. electricity price forecast, wind power forecast, photovoltaic output forecast, etc, have great impacts on the safe, stable and economic operation of power system, which has obtained more and more attention since the rapid development of smart grid [3]. The basic principles and algorithms of the above forecast problems are similar and they are the application of forecast on power system. It is important to introduce these hot issues in teaching to extend the course context, which would help to train students' ability of innovation and practicing.

All in all, this paper would discuss the ways and effects of teaching reformation of Power System Load Forecast, from the perspective of course context, teaching methods, evaluation methods, etc, to satisfy the students' needs, inspire students' enthusiasm and improve students' ability of innovation and practicing, which would make teaching keep up with the development pace of the smart grid.

\section{THE CHARACTERISTICS OF POWER SYSTEM LOAD FORECAST} COURSE

\section{A. Tight Combination of Power System Load Forecast Course and Mathematics}

The development of forecast course and Mathematics are closely connected. Firstly, the mathematical theories in forecast are emphasized because forecasting is a procedure of mathematical modeling according to the popular teaching materials of load forecast, including the one written by Professor Niu Xiaodong in North China Electric Power University and the book which Professor Kang Chongqing from Tsinghua University wrote; Secondly, existing forecast methods are mostly based on mathematical theories, such as elastic coefficient method, exponential smoothing, grey prediction, time series, neural network, support vector machine and wavelet analysis and so on; Then the measure of bad data identification as well as monitoring applied to processing prepared statistics for forecast is based upon mathematical principles, too; At last, mathematical numerical calculation is basis of error analysis still when valuing the forecast results. It is thus clear that solid foundation of Math is essential for load forecast class, and this class will do good help in restrengthening mathematical basic theories and measures the other way round. Nevertheless, there involves plenty of algorithms and mathematical theories which can not be explained concisely within limited teaching hours. As a result, 
it turns out to be a problem of designing and choosing class content, which is worth thinking, to let students form ideas of combining forecast and Math.

\section{B. Tight Combination of Power System Load Forecast Course and Programming}

The realization of the ultimate model requires the calculation, which is based on computer programming especially by Matlab [4-5]. There are numbers of tool cabinets in Matlab suitable for forecast, based upon which calculation and development programming is very convenient. Also, invoking mutually with other programs, it is of great convenience to improve algorithms. Furthermore, the function of drawing in Matlab is so powerful to satisfy the needs of analysis and display of forecast results. Consequently, students are supposed to master Matlab in some level according to a good design of the class, able to calculate forecast problem with Matlab and most importantly, lay a good foundation for the following course design, graduation project as well as postgraduate learning.

\section{Large Number of the Elective Students of Power System Load Forecast Course}

There are always large numbers of students electing Power System Load Forecast, and the class scale is big correspondingly. On one hand, this phenomenon is owing to the setting of the courses, on the other hand, that is because big emphasizes are put on this course and its great practical application value, which keep the load forecast course popular. Avoiding the classroom capacity exceeds, the student numbers in classrooms are limited. But in fact there are always students who fail to elect this course attend the class. Thus how to set the class capacity to satisfy study needs is a problem which teaching reformation should work out.

\section{Single Evaluation Mode in Power System Load Forecast Course}

Before the teaching reformation, the evaluation mode of Power System Load Forecast is single, either by examination or by writing a paper. If the class ends with a examination, the significance of programming is unable to show owing to the limited content; If everyone hands in a paper, considering no concrete judging standard, a big majority of the students will work out reviews without making full use of knowledge learned in the class and practicing programming.

\section{E. The Impact of Smart Grid Environment to Power System Load Forecast Course}

With the development of smart grid, large mounts of distributed generation are connected to the power grid, especially wind power and photovoltaic. Additionally, in user side, single fixed power price are gradually replaced by TOU power price and real-time pricing. As a result, wind power forecast, photovoltaic output forecast and power price forecast have become hot forecast issues in the background of smart grid.

\section{REFORM IDEAS OF ELECTRIC POWER SYSTEM LOAD FORECAST COURSE}

\section{A. Reform of Teaching Content}

In the setting of teaching content, previous way of taking textbooks materials as main lecture content is changed. Based on textbooks, contents regarding automation of power grid dispatching are added to enhance knowledge about both application influences on power system of forecast; Besides, power price forecast is added, learning content of real-time pricing, pointing out the relationship between power price forecast and load forecast as well as analyzing the correlations; Furthermore, wind power forecast is added, and factors affecting wind power output are analyzed and developing tendency of wind power is further discussed; Additionally, photovoltaic generation forecast is added, analyzing influential factors regarding output and corresponding developing tendency is taken into consideration; Moreover, uncertainties in operation and dispatch brought from forecast uncertainties and corresponding solutions are analyzed under the background of smart grid.

\section{B. Reform of Teaching Methods}

In teaching methods, previous alone class lecture is improved with multiple supplementary teaching means.

1) Development of teaching assistant system: the system can basically integrate existing mature forecast algorithm and operate with friendly interface, and in teaching process, operating the software can demonstrate effectiveness of practical algorithm to students and enhance knowledge of both understanding of algorithms and comparison results of effectiveness of different algorithms.

2) Settings of public teaching email boxes: through establish of public email, resources of both teachers and students can be shared and latest bibliography, program and ideas can be co-discussed.

3) Application of questionnaire: considering there is much content in research subject, to acquire ideas of students and their degree of mastering courses, accordingly, questionnaire in each class mainly consisting of choice questions is carried out so that learning contents are consolidated and students situations are achieved through 5 minutes[6].

\section{Reform of Examination Methods}

Regarding examination methods, diversified exam system is implemented. Students are allowed to choose exam methods, which include session reports, open-book exam, closed-book exam, grouped seminar reports and individual defense based on students opinions acquired from questionnaire, and regular grades are reflected through questionnaire and log in class. As for session reports, set upper limit of the grades 80; As regard to grouped seminar reports, students choosing this project can freely team up with 3 people in each group, firstly a specific forecast case is selected through teachers' interview, then study and analyses of programming are carried out, finally make ppt to demonstrate and answer questions in class during a given time, and corresponding grades are determined by teachers and the rest of the students. The overall ideas of individual defense 
are almost the same as grouped seminar reports, while defense and grades are only determined by teachers.

\section{RESUltS ANALYSIS OF POWER SYSTEM LOAD FoRECAST COURSE TEACHING REFORMATION BASED ON QUESTIONNAIRES}

The 3-year course reformation practice of the load forecast of power system has made great progress, especially for the utilization of questionnaire, which improve the interactive communication between teacher and students.

\section{A. Design and Analysis of Questionnaires before Class}

This questionnaire is designed for the first class of the course, aiming at gathering information of students about reasons to learn the course, majors, mathematical abilities, programming ability, expectations of learning ways and examination ways, etc. The results of the questionnaire about reasons to learn the course are shown in Fig.1, which indicates that most students are more interested in learning algorithm and programming.

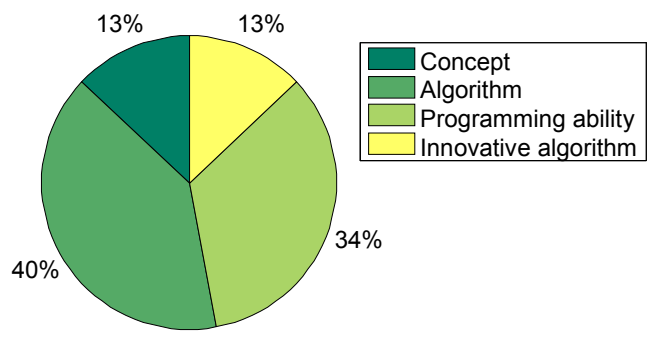

Fig. 1. The analysis of the questionnaires of reasons to learn this course

\section{B. Design and Analysis of Questionnaires in Class}

This questionnaire is designed for each class, according to the teaching content, to examine the mastery degrees of students. Take the teaching of wind power forecast as an example; the questions in the questionnaire are mainly about influence factors of wind power output, characteristics of wind power units, wind power integration, development of wind power and application of wind power forecast. The results of the questionnaire about the main factor that affects wind power output are shown in Fig.2, which indicates that most students have a right answer (wind speed) after the class.

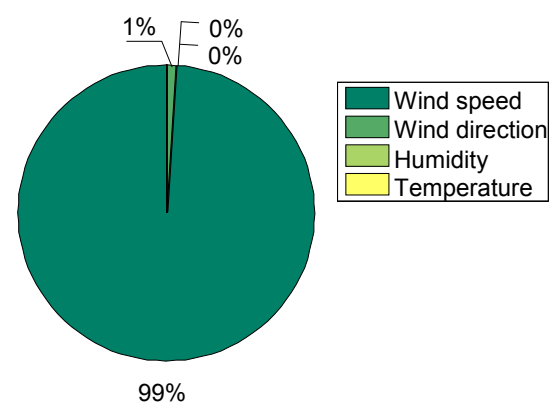

Fig. 2. Analysis of the questionnaires of the main factor that affects wind power output

\section{Design and Analysis of Questionnaires after Class}

Questionnaires after class are mainly aimed at analyzing students' integrated evaluation on the subject after the course. Fig.3 shows part of investigation and analysis about classending modes according to the questionnaire, where more than half of the students chose exam as class-ending mode, and 24 percentage of the students chose grouped seminar report, while only 13 percentage chose class-ending paper, illustrating that only a small part of students requested fewer conditions for grades, while a larger proportion of students dared to try reformation, hoping to improve both good grades and practical programming and lecture abilities through practical operation. Fig. 4 shows the final analysis of grades satisfaction degree, in which most of the students are satisfied with final grades and only rare students feel rather ordinary, indicating students' recognition for teaching and reformation.

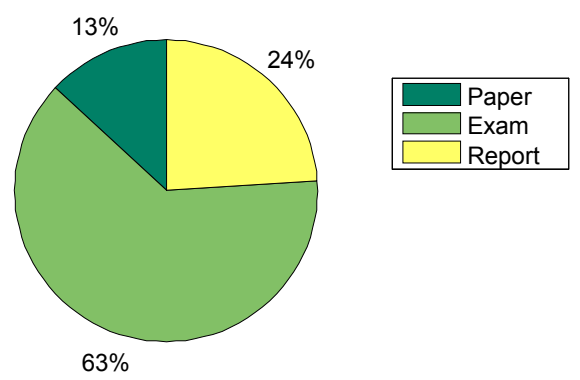

Fig. 3. The investigation of the class-ending modes

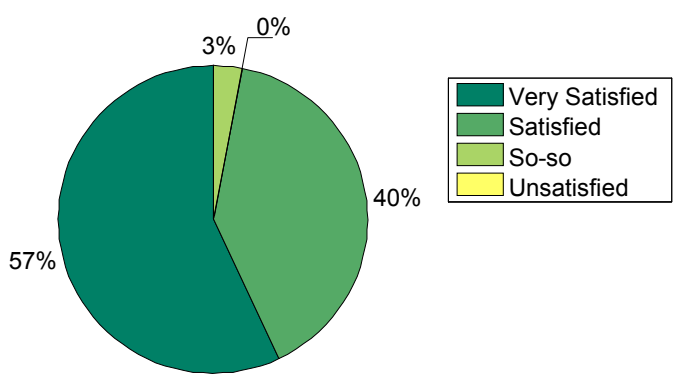

Fig. 4. The analysis and investigation of the final scores satisfaction degree

There are total 8 questionnaires in courses reformation. 180 questionnaires are sent out each time and validate questionnaires can make up over $90 \%$, manifesting that students actively collaborate with questionnaires. Through timely analysis of questionnaires and their results, teachers can adjust teaching contents and methods according to demand and knowledge mastering degree of students in time.

\section{CONCLUSION}

This paper has proposed a new design thought of course reformation of Power System Load Forecast, based on the analysis of this course's characteristics and the new requirement under the background of smart grid: 
1) Enrich course content by introducing topics of automation of electric network management, electricity price forecast, wind power forecast, photovoltaic output forecast, etc;

2) Develop and employ software of teaching demonstration, provide public email and adopt questionnaire to ensure interactive communication;

3) Reform examination ways and students could choose one or more from ways provided.

The design and analysis of questionnaire have been conducted during the whole process of teaching reformation, which has proved that the reformation has made great progress and provided new thoughts for other course reformations of Electrical Engineering.

\section{REFERENCES}

[1] Chongqing Kang, Qing Xia, Mei Liu, "Power system load forecasting," Beijing: China Electric Power Press, 2008.

[2] Dongxiao Niu, Shuhua Cao, Jianchang Liu and Lei Zhao, "Power load forecasting technology and its application," Beijing: China Electric Power Press, 2011.

[3] Huiling Li, Xiaomin Bai, Wen Tan, Weijie Dong and Nan Li, "Research on Dynamic Economic Dispatch Based on Smart Grid," Power System Technology, 2013, 37(6): 1547-1554.

[4] Zhexue Ge and Zhiqiang Sun, "Neural network theory and MATLABR2007 application," Beijing: Electronic Industry Press, 2007.

[5] Jinwu Zhuo, "Application of MATLAB in mathematical modeling," Beijing: Beihang University Press, 2013.

[6] Lihui Liu, "Questionaire analysis of college English teaching reformation," Jian Nan Wenxue, 2011, 10: 93-94. 